\title{
A UTILIZAÇÃO DE POLICLORETO DE VINILA (PVC) NA CONSTRUÇÃO DE MINI- ABRIGOS METEOROLOGICOS PARA APLICAÇÃO EM CAMPO
}

\author{
CASTELHANO, Francisco J. - francisco_castelhano@hotmail.com \\ LABOCLIMA - Departamento de Geografia / UFPR - Universidade Federal do Paraná - \\ ROSEGHINI, Wilson F. F. - feltrim@gmail.com \\ LABOCLIMA - Departamento de Geografia / UFPR - Universidade Federal do Paraná -
}

\begin{abstract}
RESUMO. Este trabalho tem como objetivo auxiliar as pesquisas de campo em climatologia, facilitando a logística dos equipamentos utilizados na coleta de dados, além de buscar uma redução de gastos ao empregar materiais mais duráveis e leves. Foram efetuadas analises estatísticas comparativas entre os mini-abrigos tradicionais em madeira e a proposta de utilização do PVC, calibrados em conjunto com a estação automática do INMET localizada no Centro Politécnico da UFPR, em Curitiba, durante os meses de setembro e outubro de 2011. Os dados foram coletados em situações meteorológicas diversas (chuva, altas e baixas temperaturas e umidade), explicitando ao final da análise uma alta correlação entre os dados oficiais e os coletados pelos sensores dos mini-abrigos. Assim, concluiu-se que a aplicação dos mini-abrigos de PVC possibilita alta acurácia dos dados coletados em campo, mostrando-se altamente confiáveis para aplicação em pesquisas.

PALAVRAS-CHAVE: Pesquisas de campo; Mini-abrigos; PVC; Coleta de dados.
\end{abstract}

UTILIZATION OF POLYVINYL CHLORIDE (PVC) TO BUILD METEOROLOGICAL MINISHELTER FOR APPLICATION IN FIELD COLLECTION

\section{ABSTRACT}

This work aims to help the research in climatology, facilitating the logistics of the equipment used in data collection, and seek a reduction in costs by use more durable and lightweight materials. Comparative statistical analyzes were performed between the traditional mini-shelters of wood and the proposed use of PVC calibrated with the automatic station of INMET located on Centro Politecnico in UFPR, Curitiba, during the months of September and October 2011. Data were collected in different weather conditions (rain, high and low temperatures and humidity), explaining the final analysis a high correlation between the official data collected by sensors and mini-shelters. Thus, it was concluded that the application of mini-shelters of PVC allows a high accuracy of the data collected, showing to be highly reliable for use in research.

KEY WORDS: Data collection; mini-shelters; PVC; research in climatology.

\section{INTRODUÇÃO}

A obtenção de dados primários em climatologia compete como a melhor fase de uma pesquisa para alguns. Tal tarefa se incumbe de uma responsabilidade gigante dentro da pesquisa, uma vez que, toda ela se estruturara em função de tais resultados obtidos, e qualquer detalhe omitido pode vir a influenciar os resultados finais. Segundo Tarifa et al. (2009), "...o campo possibilita a aproximação com real, o entendimento na escala do homem, do espaço geográfico e social".

Para outros, no entanto, esta parte é justamente o oposto. A saída à campo para a realização de pesquisas por ser fatigante acaba por não ser a preferida de muitos pesquisadores. Em se tratando da climatologia, a realização de um trabalho de campo, visando à obtenção de dados primários, envolve muito mais do que somente observação e análise, normalmente visam à obtenção de dados de umidade relativa do ar, chuva e temperatura, por exemplo, dados estes que só podem ser obtidos através do uso de aparelhagem especifica para tal fim, que ficam dispostos nos chamados mini-abrigos meteorológicos distribuídos nos locais de pesquisa.

Azevedo (2001) cita que no caso do clima urbano a problemática é ainda maior, uma vez que, neste ambiente, em função das rugosidades geradas pela cobertura e uso do solo, que se somam as edificações e ações antrópicas, é gerado um complexo climatológico único, que aumenta a responsabilidade da escolha dos pontos de coleta.

No caso da cidade, não só a questão de sua complexidade climatológica deve ser pensada, mas também a questão da segurança é fator fundamental para a escolha dos pontos de coleta. Os equipamentos meteorológicos de coleta de dados normalmente apresentam um valor elevado, e não podem ser simplesmente deixados sem a supervisão de um responsável.

Segundo Varejão-Silva (2006), os abrigos utilizados normalmente seguem as ordenações da Organização Meteorológica Mundial (OMM), assim sendo, estes são confeccionados em madeira, compondo-se de duas caixas, uma dentro da outra, possuindo venezianas em sentidos opostos, que permitem a ventilação, porém não permitem que o vento bata diretamente sobre o termômetro, pintados de tinta branca, com o intuito de diminuir a absorção energia. 
A temperatura do ar deve ser mensurada à sombra, em local ventilado e protegido de precipitação (Tubelis e Nascimento, 1986). Para atender a estes critérios, usualmente o instrumento é colocado em um abrigo meteorológico pintado de branco e com venezianas de ventilação, posicionado a 1 metro e meio acima do solo, em área aberta com grama, longe de árvores e outros obstáculos.

A utilização da madeira como componente principal na confecção de tais abrigos nos faz chegar ao porque deste trabalho. A falta de praticidade do equipamento, em função de seu peso, tamanho e formato é um dos principais problemas encontrados durante uma pesquisa de campo (Figura 1 ).

Além destes em presença de chuva, situação corriqueira em uma pesquisa de campo, a madeira absorve uma quantidade muito grande de água, o que por ventura pode interferir nos valores medidos no termômetro, modificando os resultados finais, além de afetar a durabilidade do equipamento.

No caso dos mini-abrigos, busca-se na sua construção a mesma confiabilidade dos resultados obtidos nos abrigos meteorológicos oficiais.

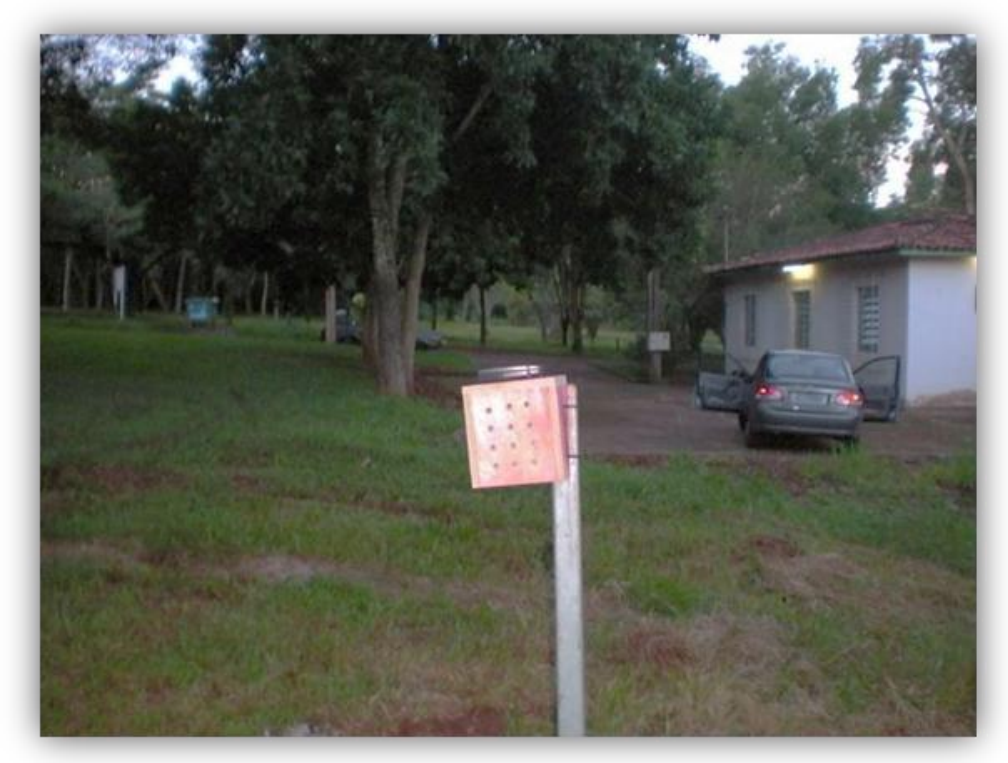

Figura 1

Mini-abrigo tradicional de madeira utilizado

Fonte: trabalho de campo

\section{Objetivos}

No trabalho de campo, em que o alvo de pesquisa é dinâmico como a climatologia, o desenvolvimento de novas idéias e materiais utilizados deve seguir a mesma premissa.

Assim sendo, o que se propõe neste trabalho é um novo tipo de mini-abrigos meteorológicos, utilizando-se de novos materiais, visando, sobretudo, sanar estes problemas através da utilização de um material mais barato, prático e leve para ser transportado, facilitando o trabalho para os pesquisadores ao mesmo tempo em que se mantém a confiabilidade dos dados coletados.

\section{Materiais e métodos}

Esta proposta de abrigo utilizou como único material o PVC, constituído em sua essência por $57 \%$ de cloro, derivado do cloreto de sódio, e $43 \%$ de eteno, derivado do petróleo. Apresenta uma densidade baixa - cerca de $1,4 \mathrm{~g} / \mathrm{cm}^{3}$ - alta resistência a fungos, bactérias e roedores, e apresenta grande nível de isolamento, tanto elétrico quanto térmico (PVC, 2012).

Em relação ao seu calor especifico, a quantidade de energia necessária para se elevar a temperatura do material é de $0,96 \mathrm{Kj} / \mathrm{Kg}{ }^{\circ} \mathrm{C}$, enquanto que o da madeira sofre influência direta da umidade, aumentando gradativamente com o aumento desta. A madeira totalmente seca no geral, tem um calor específico de aproximados $1,3 \mathrm{Kj} / \mathrm{Kg}^{\circ} \mathrm{C}$, cabendo 
ressaltar que este valor depende do tipo de madeira a ser analisado, segundo Favero et al. (2007).

Outro aspecto que interferiu na escolha deste material foi à possibilidade de tê-lo na cor branca, sua alta resistência a umidade, baixo peso e principalmente a facilidade de montagem e transporte se comparado a madeira.

Assim sendo, para se comprovar a eficácia da utilização deste material, foram criados modelos que seguissem as proposições da OMM, sendo testados simultaneamente com os já tradicionais de madeira. Tais abrigos foram instalados na mesma localidade e durante o período analisado registraram dados de temperatura concomitantemente com as estações automática e convencional oficiais do Instituto Nacional de Meteorologia (INMET), localizada no Centro Politécnico da Universidade Federal do Paraná.

O primeiro passo dos testes, portanto, foi à calibragem dos equipamentos utilizados, os quais coletaram dados de temperatura por aproximadamente dez dias, período suficiente para registrar diferentes condições atmosféricas de altas e baixas temperaturas, além de dias chuvosos e secos.

Os termômetros utilizados foram do modelo HOBOU $12^{1}$ (figura 2 ), sendo colocados dois em cada abrigo para evitar a perda de dados com possíveis falhas, além de aumentar o número de amostras para os cálculos estatísticos de correlação e significância.

Vale ressaltar também que os termômetros digitais HOBO foram programados para registrar a temperatura a cada 15 minutos, enquanto os dados das estações do INMET (automática e convencional) disponibilizaram os dados horários e as 9, 15 e 21 horas, respectivamente.

Assim, foram efetuadas médias dos valores dos HOBO para ajusta-las a escala temporal das estações oficiais, possibilitando a correlação.

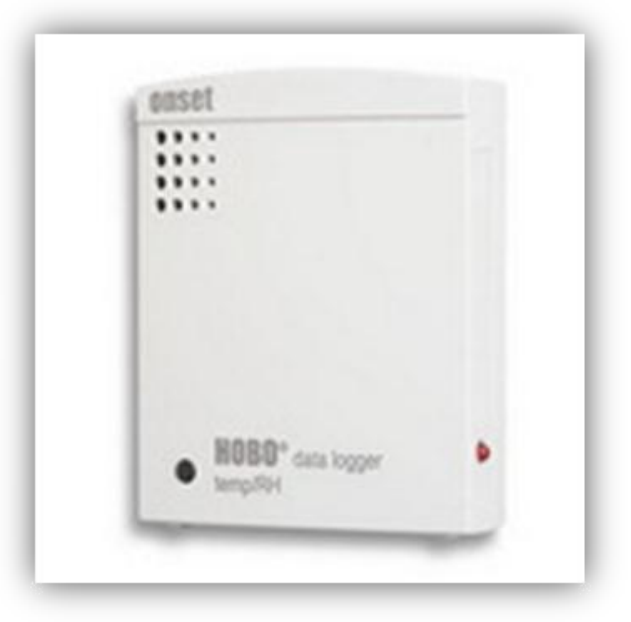

Figura 2

Termômetro digital HОВО U12

Fonte: www.onsetcomp.com

Quanto à construção dos abrigos de PVC, dois modelos diferentes foram confeccionados. A confecção destes se embasou na utilização de uma caixa de esgoto sifonada circular sem a tampa superior, com medidas de $15 \times 15 \mathrm{~cm}$ (Figura 3 ).

\footnotetext{
${ }^{1}$ Marca registrada Onset Data Loggers - www.onset.com
} 


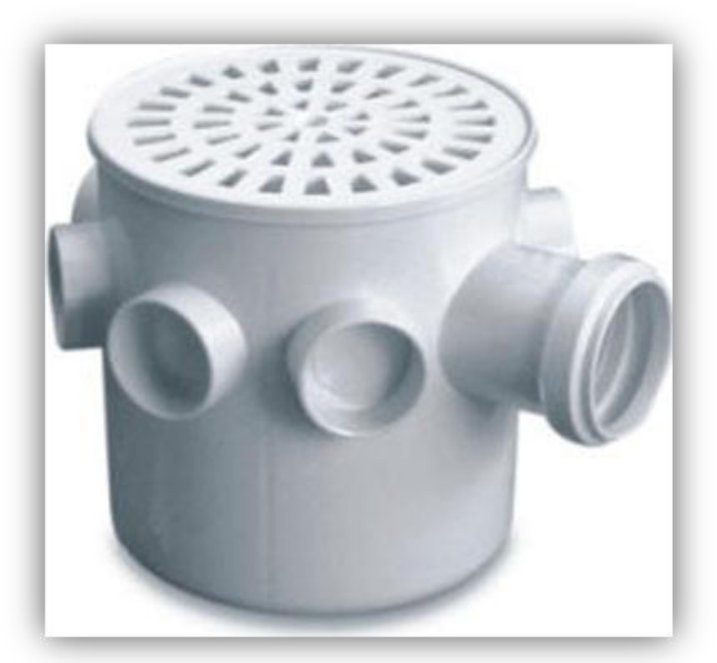

Figura 3

\section{Caixa de esgoto sifonada, Medidas $15 \mathrm{~cm} \times 15 \mathrm{~cm}$}

Fonte: www.tigre.com.br

No primeiro modelo, o qual chamaremos " $A$ " (figura 4), somente alguns furos foram feitos na estrutura da caixa, totalizando três linhas de furos de $5 \mathrm{~mm}$, que permitam a passagem e circulação do vento para o interior do compartimento.

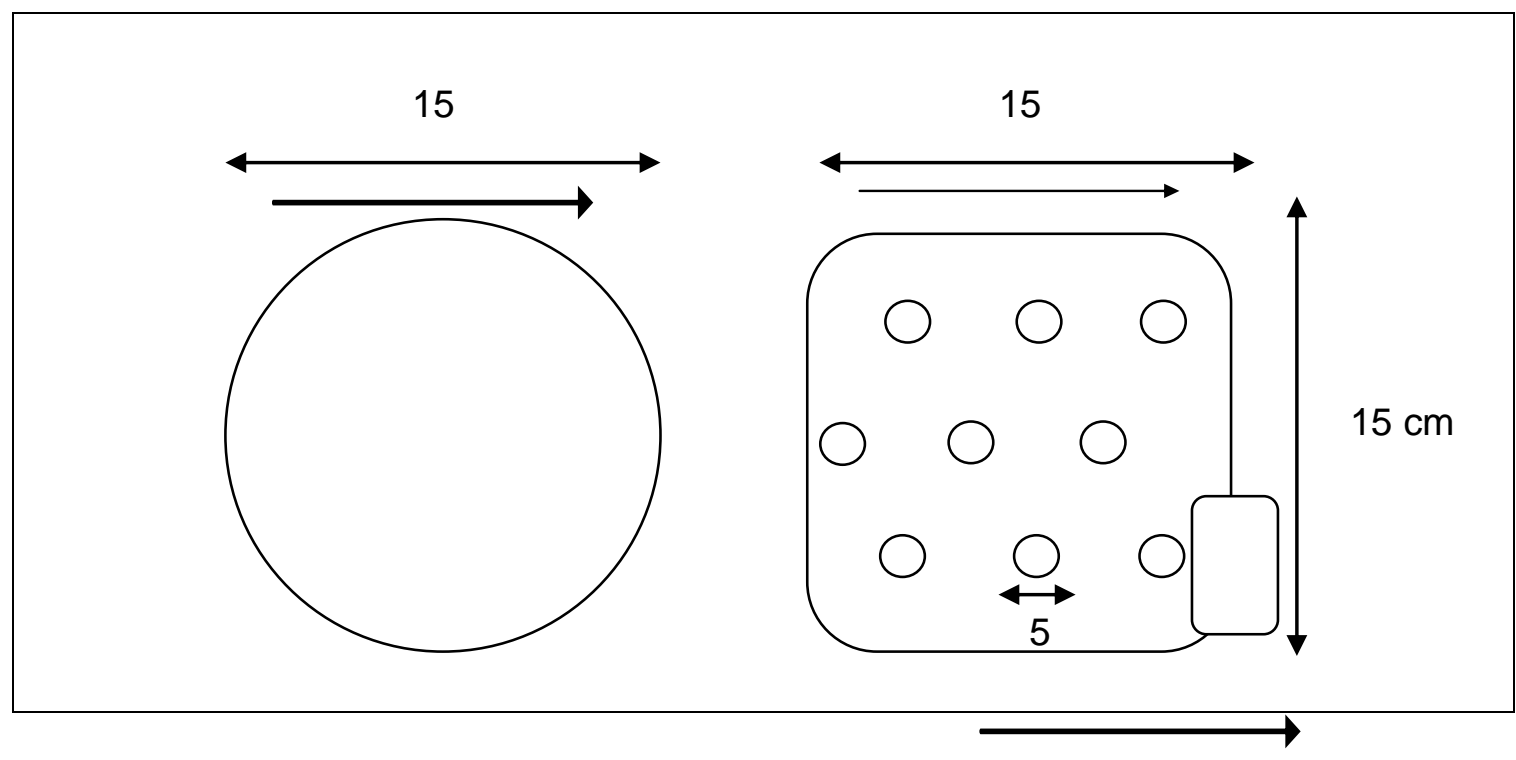

Figura 4

Esquema representativo do modelo "A", visão inferior e lateral (com furos)

Já no segundo modelo, ao qual chamaremos modelo "B", alem destes furos, uma nova cúpula foi instalada no interior da caixa, formando uma parede de proteção interna (figura $5 \mathrm{~A}$ ). Tal parede se distanciou aproximados $2,5 \mathrm{~cm}$ da caixa e também foi furada, de forma em que os furos não se sobrepusessem aos da parede exterior, permitindo assim uma ventilação indireta.

Os modelos foram instalados em uma haste e fixadas sobre uma base de PVC, ficando 1,5 metros acima do solo (Figura 5 B). 


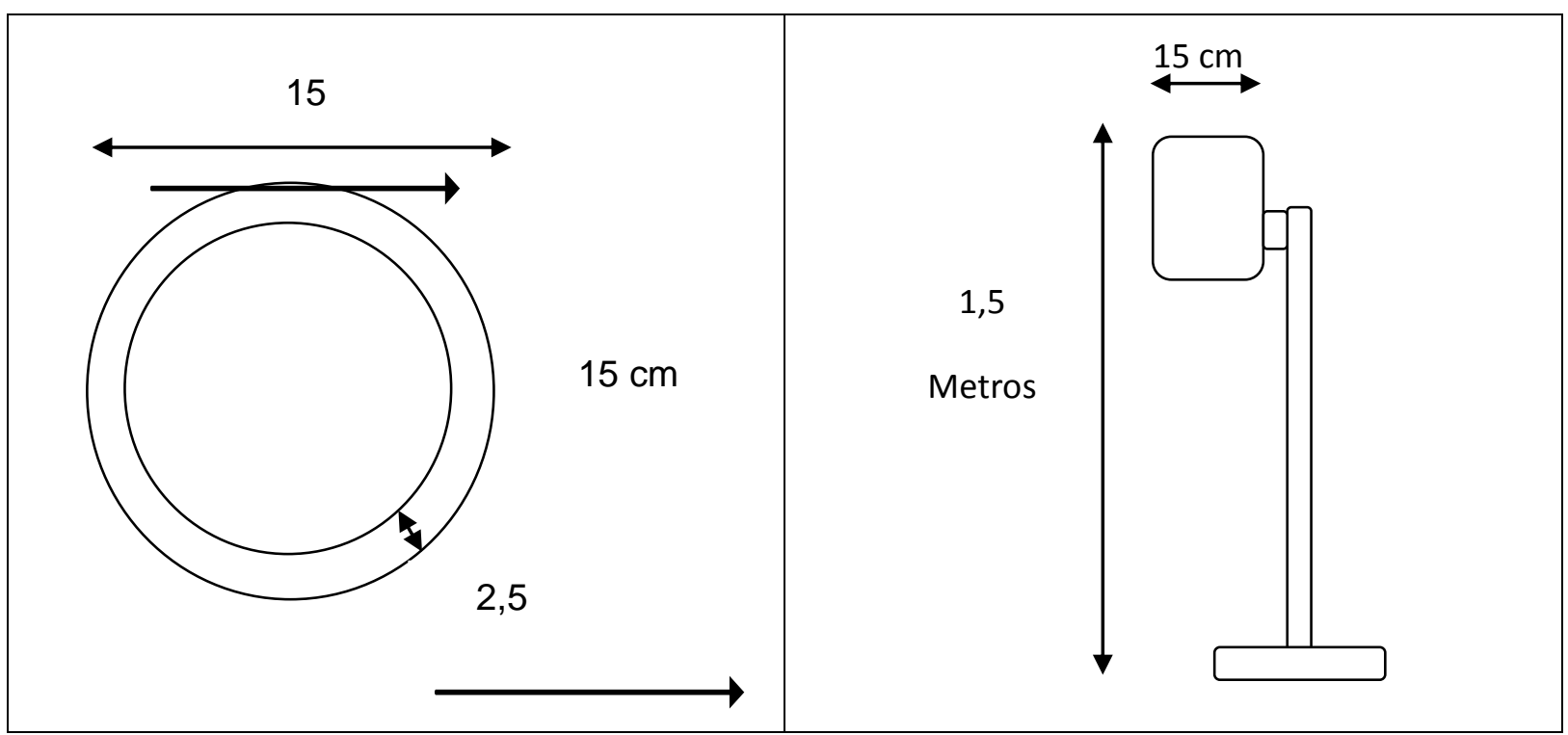

Figuras 5 A e B

Esquema representativo do modelo "B" (Figura 5 A) com visão inferior e lateral (com furos); haste em PVC com suporte para os mini-abrigos (Figura 5 B)

Após a construção dos abrigos, foram iniciados os testes. Esta fase consistiu na verificação da efetividade dos novos abrigos em comparação aos de madeira (miniabrigos já existentes no laboratório).

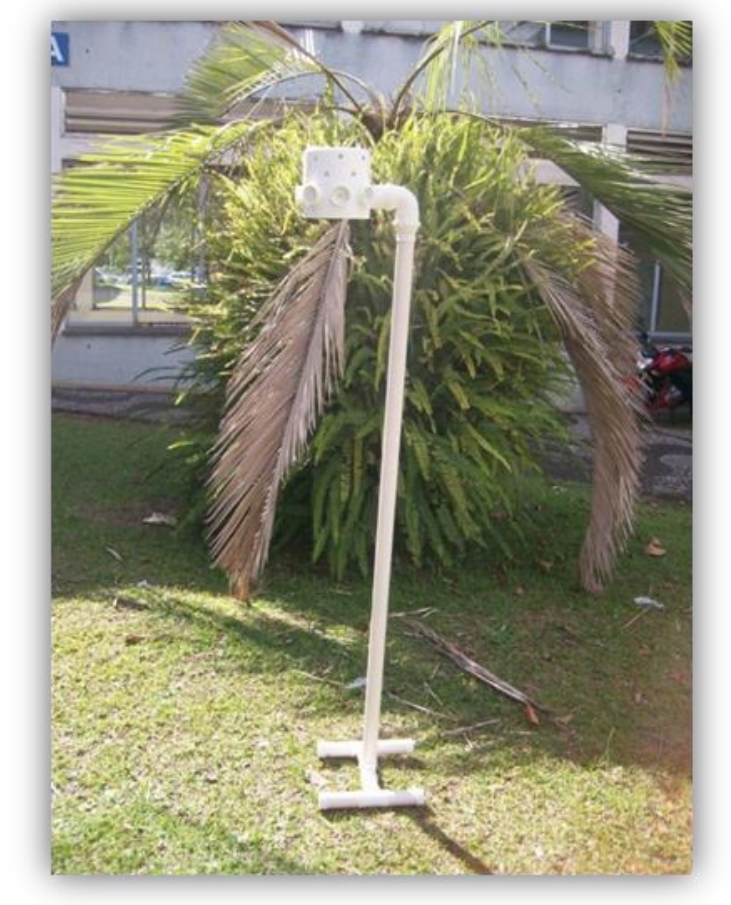

Figura 6

Modelo "A" do mini-abrigo utilizado no experimento

Para tanto, foram feitas duas baterias de testes. A primeira comparou as leituras do abrigo modelo " $\mathrm{B}$ " juntamente ao abrigo de madeira tradicional, enquanto a segunda bateria comparou o modelo "A" (figura 6) e o mesmo abrigo de madeira. Todos os testes foram efetuados no mesmo local onde se situa a estação meteorológica convencional e automática do INMET, no Centro Politécnico da UFPR.

Assim sendo, após sete dias de testes entre os dias 19/09/2011 até 26/09/2011, os primeiros resultados foram obtidos e comparados em relação aos abrigos e a estação oficial. 
Em seguida, apenas o modelo " $\mathrm{A}$ " foi posto em teste por oito dias, entre os dias 26/09/2011 e 03/10/2011.

Por fim, após a coleta de todo material e da criação do arcabouço, foram aplicados cálculos estatísticos de correlação e significância, possibilitando assim evidenciar a confiabilidade dos dados extraídos dos abrigos ao compará-los com os dados do INMET.

\section{Resultados}

De acordo com os cálculos efetuados, obteve-se alta correlação entre as leituras geradas pelos sensores digitais dos mini-abrigos de PVC e de madeira em relação aos dados oficiais da estação automática do INMET, como pode ser observado na Figura 7 e na Tabela 1:

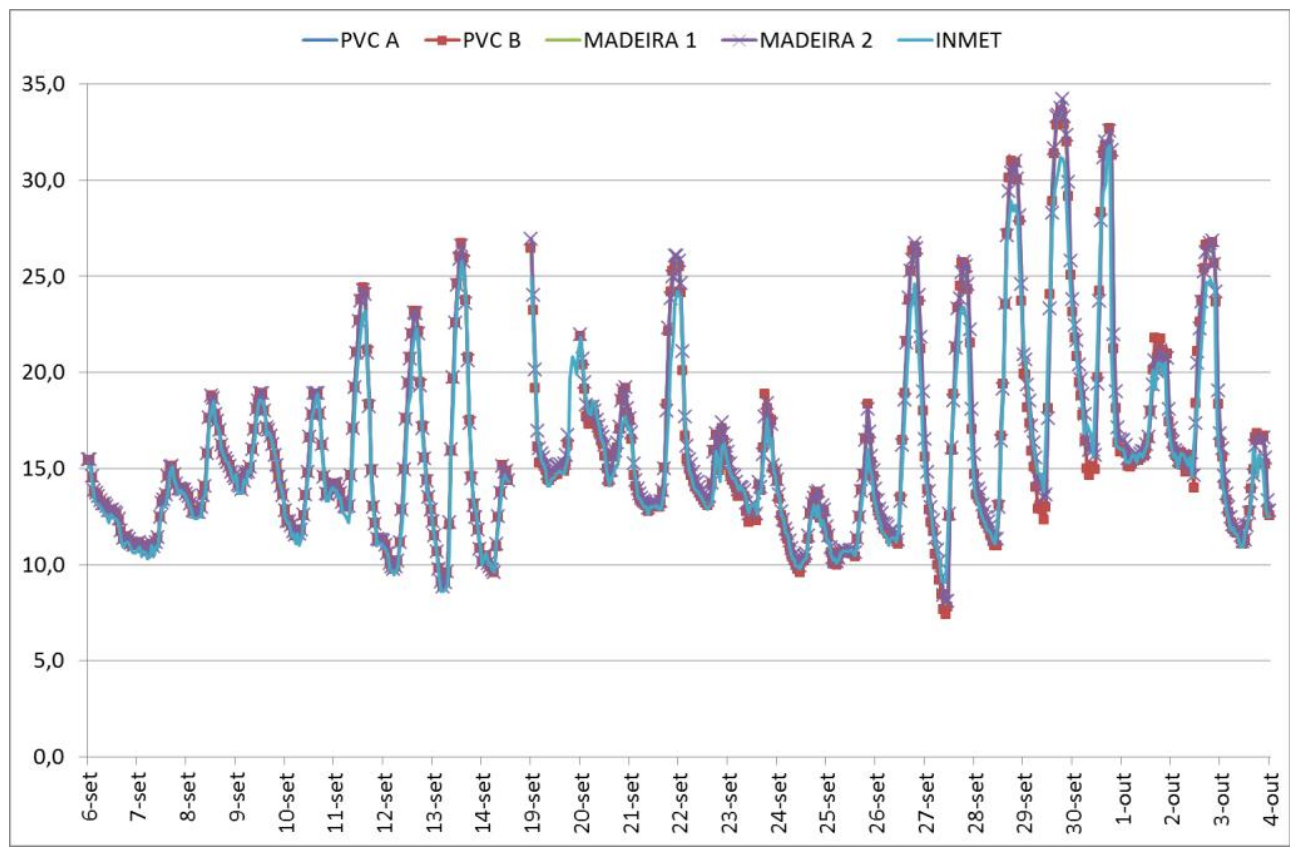

Figura 7

Variação horária das temperaturas em todos mini-abrigos e na estação automática do INMET durante o período de calibragem e análise

É importante salientar que durante o período analisado, os abrigos passaram por situações meteorológicas diversas, como períodos mais frios, úmidos e nublados entre os dias 06/09 e 10/09 e 22/09 e 25/09, além de períodos com maior amplitude térmica, secos e de grande insolação direta, conforme observado entre 11/09 e 13/09 e 26/09 e $30 / 09$, permitindo avaliar o funcionamento nas mais variadas condições meteorológicas.

Tabela 1

Correlação entre os dados dos mini-abrigos de PVC, madeira e INMET

\begin{tabular}{ccccc}
\hline & \multicolumn{2}{c}{ PVC } & \multicolumn{2}{c}{ Madeira } \\
\cline { 2 - 5 } & Modelo A & Modelo B & Sensor 1 & Sensor 2 \\
\hline Correlação Pearson & 0,986 & 0,984 & 0,986 & 0,986 \\
\hline Teste significancia & 0,994 & 0,994 & 0,994 & 0,994 \\
\hline Erro quadrático médio & 5,9 & 5,4 & 8,2 & 9,2 \\
\hline
\end{tabular}

Todas as amostras foram significantes $(P>0.99)$ com correlação superior a 0.98 , mostrando-se excelentes para utilização em campo tal como os tradicionais mini-abrigos de madeira, sem diferença significativa se comparados aos dados do INMET.

Já no caso do erro quadrático médio, a acurácia observada foi maior nos dados dos miniabrigos de PVC, evidenciando maior estabilidade na oscilação dos valores durante o período analisado se comparados aos dados obtidos nos abrigos de madeira, talvez por 
estes últimos sofrerem maior influência da umidade, devido a capacidade da madeira em absorver água.

Ao analisarmos os gráficos de cada sensor separadamente nas figuras 8, 9, 10 e 11, os resultados reforçam a alta correlação dos abrigos já mencionada.

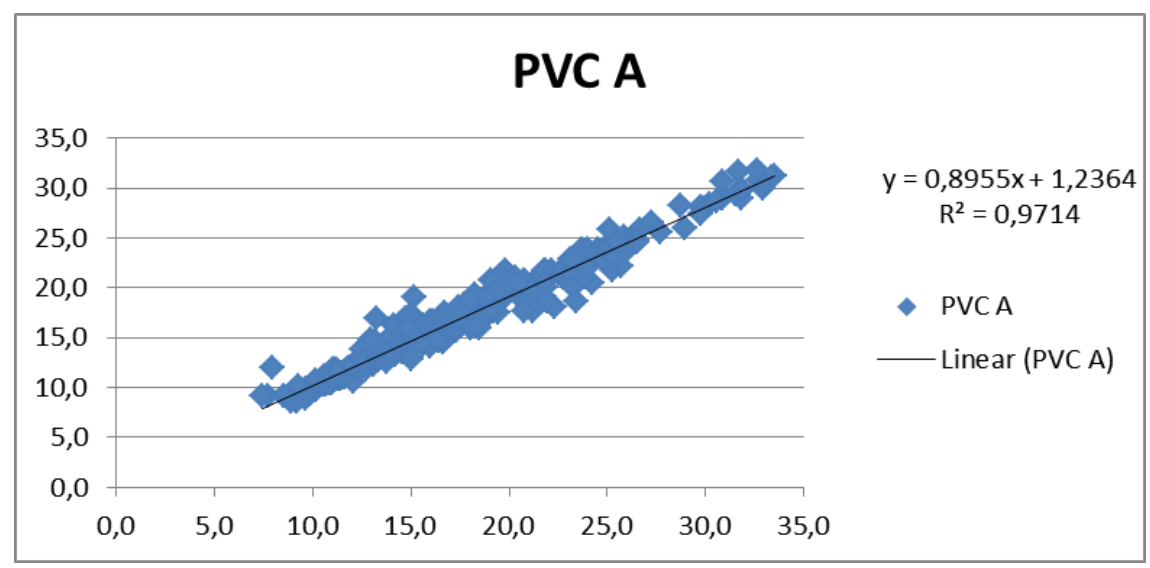

Figura 8

Correlação entre os dados do mini-abrigo de PVC "A" e da estação automática do INMET

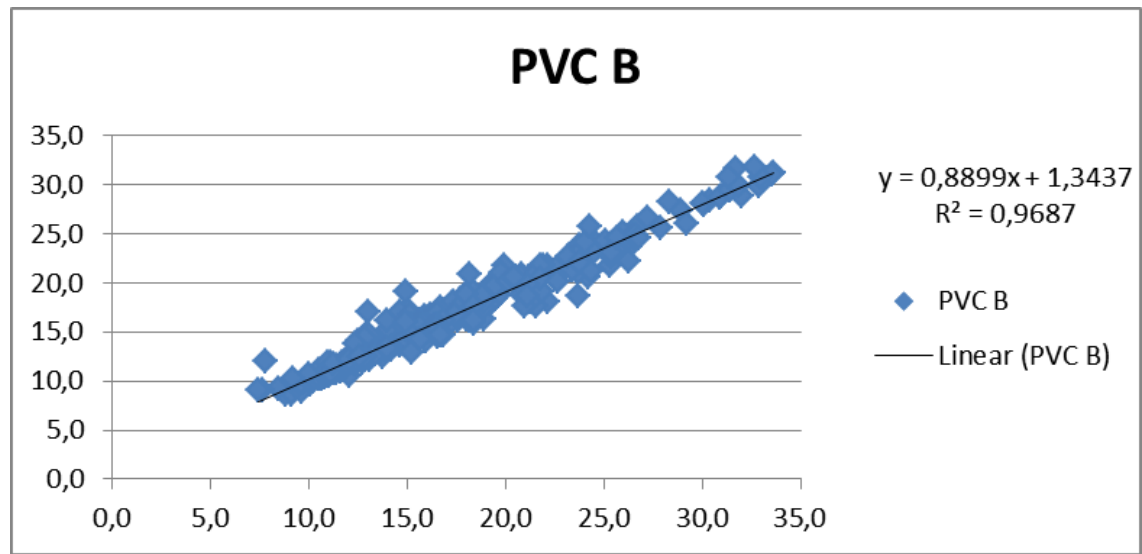

Figura 9

Correlação entre os dados do mini-abrigo de PVC "B" e da estação automática do INMET

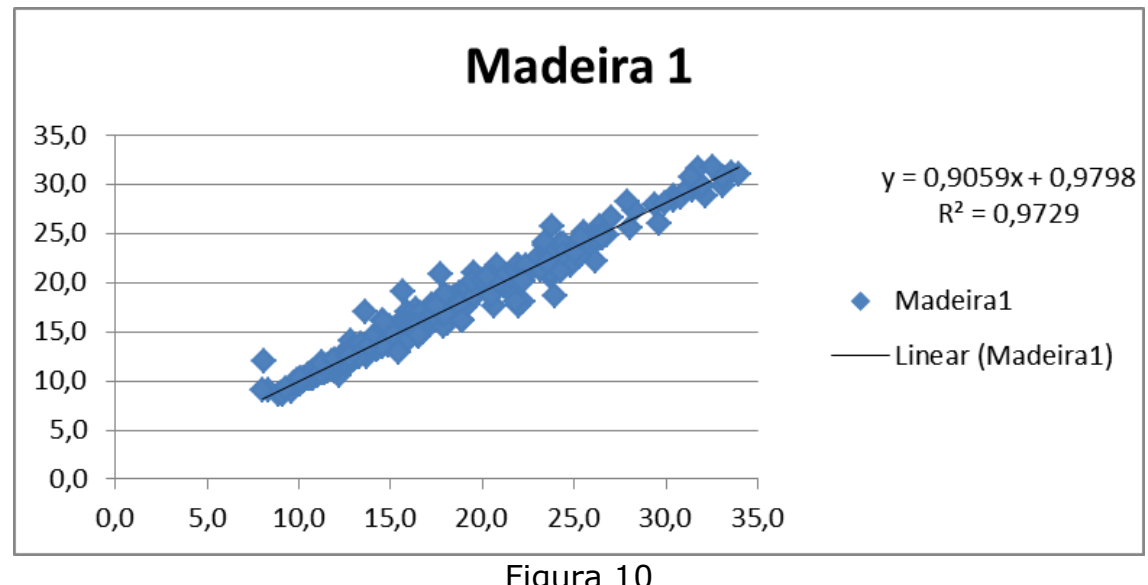

Figura 10

Correlação entre os dados do mini-abrigo de madeira 1 e da estação automática do INMET 


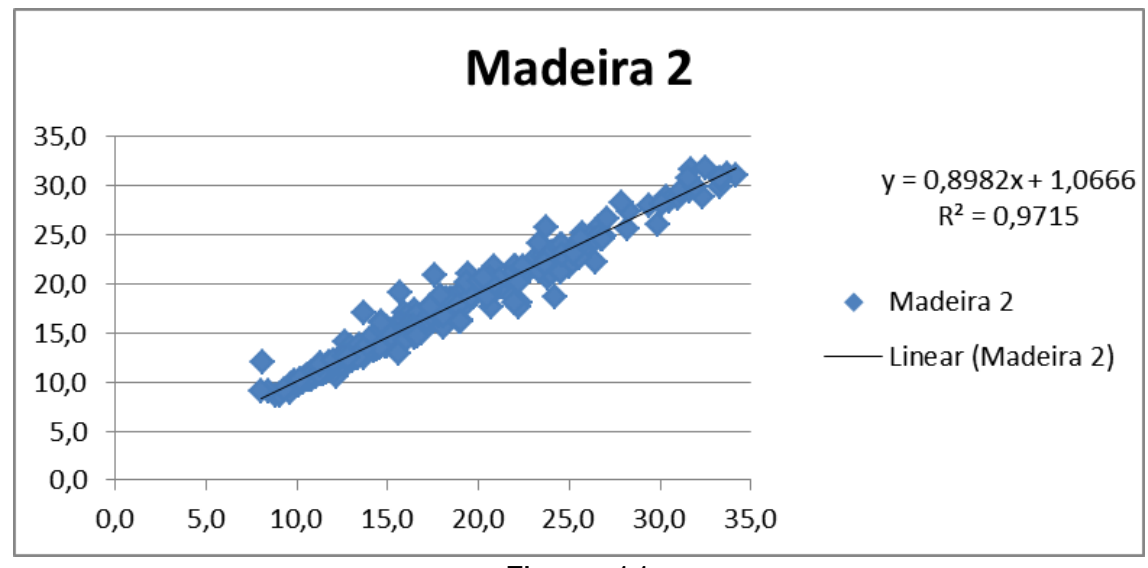

Figura 11

Correlação entre os dados do mini-abrigo de madeira 2 e da estação automática do INMET

\section{Conclusão}

Os resultados alcançados mostraram-se favoráveis à aplicação do PVC para a confecção de mini-abrigos e uso em pesquisa de campo, evidenciando uma grande similaridade com os dados oficiais registrados pela estação automática do INMET, referendando assim a confiabilidade dos mesmos.

Estes resultados também propiciam uma melhor logística para os equipamentos, aumentando a eficiência no transporte e evitando maiores custos, inclusive na construção e na durabilidade do material. Evidentemente, faz-se necessário um aprofundamento maior de estudos neste contexto para enriquecer ainda mais os resultados encontrados, inclusive considerando-se variáveis como umidade, insolação e radiação.

\section{Agradecimentos}

Os autores agradecem ao Instituto Nacional de Meteorologia (INMET) através de sua estação no campus Centro Politécnico, ao Laboratório de Climatologia (Laboclima) da Universidade Federal do Paraná (UFPR) e ao Prof. Dr. Francisco Mendonça por disponibilizarem espaço, equipamentos e sugestões para o estudo, e ao senhor Itamar João Castelhano pelo auxilio na montagem dos abrigos. Esperamos contribuir para que as pesquisas de campo sejam efetuadas com maior facilidade e menores custos.

\section{Referencias}

.AZEVEDO, T. R. de. Derivação antrópica do clima na Região Metropolitana de São Paulo abordada como função do ritmo semanal das atividades humanas. Tese de Doutorado, USP, São Paulo, 2001.

.FAVERO, G.C, VALLE, R.M; DUARTE, T.M, Analise Térmica de um Sistema de Combustão de Alcatrão em Fornos Retangulares para Secagem da Madeira, Anais do $8^{\circ}$ Congresso Ibero americano de Engenharia Mecânica. p. 639-646 PUC Perú, Cusco, 2007. p. 639-646

.PVC, INSTITUTO DO. Disponível em:<www.institutodopvc.org $>$. Acessado em: 25/01/2012.

.TARIFA, J.R; SETTE D.M. O Holorritimo e o trabalho de campo em Climatologia: Uma contribuição Metodológica, Anais do XIII Simposio Brasileiro de Geografia Fisica Aplicada,CD-Rom UFV, Viçosa, 2009.

.TUBELIS, A.; NASCIMENTO, F.J.L. Meteorologia descritiva. Fundamentos e aplicações brasileiras. São Paulo: Nobel, 1986.

.VAREJÃO-SILVA, M. A. Meteorologia e Climatologia. Recife: Versão digital 2,disponível em: < http://www.agritempo.gov.br> 2006. 